\title{
ELECCIONES EN HOLANDA
}

Septiembre 1989

PEDRO J. TENORIO SÁNCHEZ

UNED

I. El 6 de septiembre se celebraron elecciones a la Segunda Cámara holandesa, con los resultados que se reflejan en el siguiente cuadro:

\begin{tabular}{|c|c|c|}
\hline \multicolumn{3}{|c|}{ ELECCIONES EN HOLANDA } \\
\hline \multicolumn{3}{|c|}{ Septiembre 1989 * } \\
\hline & MAYO 1986 & SEPTIEMBRE 1989 \\
\hline CDA (Demócrata-cristiano) & 54 & 54 \\
\hline PVDA (Laborista) & 52 & 49 \\
\hline VVD (Liberal) & 27 & 22 \\
\hline 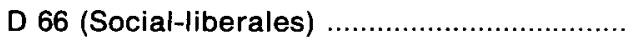 & 9 & 12 \\
\hline GROEN LINKS (Izquierda verde) ..................... & 3 & 6 \\
\hline OTROS & 5 & 7 \\
\hline
\end{tabular}

II. El parlamentarismo holandés ${ }^{1}$ se diferencia del inglés (de alternancia) por su pluripartidismo extremo y por la solución «consociativa»

1 V. C. CHIMENTI: Introduzione alla forma di Governo italiana, Rimini 1986, págs. 114 y ss.; J.-C. Colliard: Les Règimes parlementaires contemporains, Paris 1978, págs. 70 y ss.; P. LAlumiere y A. Demichel: Les règimes parlementaires europèens, París, 1978, págs. 269 y ss.; G. de Vergottinl: Diritto Costituzionale Comparato, Padova 1987, págs. 349 y ss. 
o "compromisoria" a los problemas que dicho pluripartidismo plantea o refleja.

a) La llamada «democracia consociativa» presenta, más concretamente, los siguientes rasgos: en primer lugar, un Gobierno constituido por una gran coalición entre los líderes de todas las fracciones más significativas de una sociedad polarizada; en segundo lugar, la regla del «veto recíproco", como garantía adicional de los intereses vitales de las minorías; en tercer lugar, la proporcionalidad como criterio base tanto de la representación política, como de la concesión de los empleos públicos y de la distribución de los recursos públicos; y finalmente, un alto grado de autonomia para cada grupo social en la gestión de sus propios asuntos. Sean cuales sean sus presupuestos y condiciones, un factor determinante para que se dé la consociación es el comportamiento pactista de los líderes de las distintas fracciones en que el cuerpo social está dividido (presuponiendo la obediencia de los respectivos seguidores).

La «consociación» se dio en los años 50 y 60 en Austria, en Bélgica y en Holanda. En este último país tiene sus antecedentes en el entendimiento entre católicos y protestantes desde 1878 a 1925, encuentra un hito en el llamado "tratado de paz" de 1917-1918 (que supuso un acuerdo sobre dos grandes cuestiones conflictivas: escuela y extensión del sufragio) y una institucionalización concreta en el Consejo Económico y Social, Consejo que en el caso holandés tiene una importancia equiparable a la del Gobierno o el Parlamento (Lijphart).

Por lo demás, aún después de la época consociativa en sentido estricto, gran parte de la legislación es aprobada por la oposición y discutida, en cambio, por un sector de la «mayoría».

b) El pluripartidismo, favorecido por la representación proporcional, se acrecienta regularmente por las diferencias religiosas, políticas, culturales, sociales o provinciales. En la primera mitad del siglo XIX, nacen tres partidos: católico, protestante y liberal (a diferencia, pues, de lo que ocurre en Inglaterra). A la altura de 1918, con la división de los protestantes y la llegada de los laboristas al Parlamento, encontramos cinco partidos. En 1949 serán siete. En 1976, trece. En Holanda, ningún partido alcanza mayoría suficiente para gobernar en solitario. El partido demócrata-cristiano, partido de gobierno por excelencia, o el que tras la Segunda Guerra Mundial será el otro gran partido del sistema, el laborista, difícilmente han superado la tercera parte de los escaños de la Cámara.

Pues bien, las coaliciones gubernamentales no sólo han incluido frecuentemente a estos dos partidos (en 1946-1958, en 1965-1967, o en 1973 o 
en 1981), sino que a menudo han incluido también a otros partidos sin que ello fuera necesario para alcanzar una mayoría.

La amplitud de las coaliciones, así como las divisiones internas en algunos partidos, determinan que las negociaciones para la formación del Gobierno sean singularmente largas (208 dias y seis meses en los casos de los gobiernos de Van Agt de 1977 y 1981, respectivamente).

c) Los gobiernos resultantes, tachados en ocasiones de inmovilistas (Lalumiére y Demichel) debido a la heterogeneidad de las coaliciones que los sustentan, han tenido una establlidad considerable: desde 1946 hasta 1985 su duración media ha sido de dos años.

III. Pues bien, con todos los matices que puedan derivarse del carácter consociativo del sistema, el partido laborista ha estado en la oposición al menos desde 1982. Las elecciones de aquel año se celebraron a consecuencia de la ruptura, por parte de los laboristas, de la coalición gobernante de centro-izquierda, movidos por discrepancias insalvables respecto de la orientación de la política económica y del problema de los euromisiles. Aunque tras las elecciones los laboristas eran el grupo parlamentario más numeroso, los liberales consiguieron una importante victoria (aumentaron en diez sus escaños) compareciendo ante el electorado con acuerdos preelectorales con el CDA (que sólo perdió tres escaños) que suponían un riguroso programa de resaneamiento de la economía. Se formaba así la coalición que habría de sostener desde entonces los dos mandatos de Rood Lubbers, líder del CDA, hasta las recientes elecciones.

Los recientes resultados electorales pudieran cambiar algo el panorama. EI CDA mantiene sus 54 escaños. Rood Lubbers concurría a las elecciones con un importante activo: durante sus dos mandatos el crecimiento económico ha pasado de ser casi nulo a ser de un tres por 100; ha disminuido el paro y la inflación está controlada (entre el 1 y el 2 por 100). Los liberales (VVD), que desencadenaron la crisis que dio lugar a las elecciones al discrepar sobre la financiación de un plan para la defensa del medio ambiente, parecen ser los grandes perdedores, con cinco escaños menos de los que tenian; los sufragios correspondientes se habrian desplazado hacia el CDA y los social-liberales (D 66). Estos últimos, en efecto, han ganado tres escaños. También han ganado algún escaño otros partidos menores que pueden considerarse a la derecha; más concretamente, la extrema derecha ha conseguido un escaño. El partido laborista de Win Kok ha perdido tres escaños, desplazándose los sufragios correspondientes, al parecer, hacia la izquierda. Los «Groen Links» han ganado tres escaños; pero se trata de un conglomerado de diferentes fuerzas de izquierda. Ello y el dato de que los "verdes" (Groenen) no hayan alcanzado representación, revela que el ecologismo, al haber sido asumido por todos los partidos, no parece suficiente para sustraer votos a partidos que, por tener 
posibilidades reales de acceso al poder, pueden llevar a cabo de modo efectivo los programas de protección del medio ambiente.

Así pues, aún con Lubbers como Primer Ministro, parece previsible un cambio de coalición gubernamental. Aunque no es imposible, no parece muy probable la coalición con los liberales (VVD), tanto porque fueron los que provocaron la crisis como porque la respuesta del electorado no les ha sido favorable, y además la eventual coalición no dispondría de una mayoria muy holgada. Los indicios apuntan pues, a una coalición del CDA con laboristas y social-liberales. Ahora bien, las grandes cuestiones que enfrentan al CDA con el VVD (financiación de la defensa del medio ambiente, ley de eutanasia, futuro de las cadenas privadas de televisión) son cuestiones que también separan a la democracia cristiana de los laboristas o de los social-liberales. Además, sin cuestionar la relevancia del problema del paro (algo eclipsado por el de la protección del medio ambiente) durante la campaña electoral, Lubbers ha insistido en la necesidad de liberalizar la economia disminuyendo los impuestos, en tanto que los laboristas han insistido en la defensa del Estado Social y sus prestaciones. De modo que un programa conjunto de Gobierno comportará renuncias nada desdeñables a los correspondientes partidos. 